\title{
RESENHA
}

\section{VISÕES AUSENTES NO ESTUDO DAS POLÍTICAS EDUCACIONAIS: UMA ANÁLISE DO PROCESSO DE ELABORAÇÃO DO PLANO NACIONAL DE EDUCAÇÃO}

\author{
Felippe Gonçalves Valdevino 113
}

SILVA, A. F.; RODRIGUES, M. M. (Orgs.). Novo Plano Nacional de Educação (PNE): debates e tensões. Campina Grande, PB: EDUFCG, 2013.180p. ISBN: 978-85-8001-095-4.

O livro "Plano Nacional de Educação (PNE): debates e tensões", organizado por Andréia Ferreira da Silva e Melânia Mendonça Rodrigues, é constituído por seis textos produzidos por integrantes do Coletivo de Estudos de Política Educacional114. O Coletivo, ao longo de mais de 10 anos de existência, vem investigando as temáticas "Educação Política" e "Educação Escolar", adotando como referencial teórico as contribuições do pensador italiano Antônio Gramsci.

A obra em análise propõe a analisar as "relações entre o contexto, as proposições e os principais temas que marcaram a elaboração do PNE que vigorou de 2001 a dezembro de 2010, e a conjuntura em que se desenvolve o processo de construção do novo PNE (2011-2020)" (p. 17). Publicado ainda durante o período de tramitação, no Congresso Nacional, do projeto de lei que viria a se tornar a Lei $n^{\circ} 13.005 / 2014$, que aprovou o Plano Nacional de Educação (2014-2024), o livro foi prefaciado por Nicholas Davies, para quem, "o valor maior das contribuições [da obra] é oferecer visões ausentes ou

\footnotetext{
113 Mestrando em Educação pela Universidade Federal de Campina Grande (UFCG). E-mail: felippevaldevino@hotmail.com

114 Entre as principais obras do Coletivo estão: "O empresariamento da educação: novos contornos do ensino superior no Brasil dos anos 1990" (2002), "A nova pedagogia da hegemonia: estratégias do capital para educar o consenso" (2005) e "Direita para o social e esquerda para o capital: intelectuais da nova pedagogia da hegemonia no Brasil" (2010).
} 
pouco encontradas em grande número de textos acadêmicos e mesmo sindicais atuais" (p. 7). As análises realizadas, fundamentadas no conceito gramsciano de Estado Ampliado, apontam mudanças na relação entre Estado e sociedade civil nos processos de elaboração dos dois planos nacionais de educação, desvelando a emergência no país, a partir dos anos finais do século XX, do projeto Neoliberal de Terceira Via.

A coletânea é aberta com o texto de Lúcia Maria Wanderley Neves, "Plano Nacional de Educação (PNE): alguns pontos para discussão", que traça um paralelo entre os dois planos nacionais de educação, a partir dos seguintes aspectos: processos de elaboração, o patamar mínimo de escolarização obrigatória definido, a função social da educação escolar e a relação público-privado. Destaca ainda as novas relações do Brasil com a Organização para a Cooperação e Desenvolvimento Econômico (OCDE), a participação dos representantes do empresariado brasileiro na definição da política educacional e o significado do slogan "Todos pela Educação".

Enquanto O PNE 2001-2010 foi marcado pelo embate entre dois projetos opostos de educação, o dos aparelhos privados de hegemonia vinculados aos trabalhadores da educação e o da aparelhagem estatal, o processo de elaboração do atual plano foi caracterizado pelo que Neves (2013) denomina de concertação social, sem espaço para antagonismos. Nessa compreensão, a realização da Conferência Nacional de Educação (CONAE), no ano de 2010, convocada pelo governo federal, aglutinou os sujeitos envolvidos em torno de um único projeto de educação, o do Governo Lula.

A despeito da participação da sociedade civil na CONAE (2010), o Projeto de Lei encaminhado pela Presidência da República ao Congresso Nacional "não incorporou, no conteúdo e na forma, parte significativa das teses registradas no documento final dessa conferência" (NEVES, 2013, p. 28), em contrapartida, incorporou as diretrizes do Plano de Desenvolvimento da Educação (PDE) e do Plano de Metas Compromisso Todos Pela Educação (2007). Conforme Neves (2013), o documento final da CONAE (2010) utilizou e 
ressignificou termos e conceitos oriundos dos segmentos progressistas, constituindo-se numa estratégia de sedução ao projeto neoliberal de Terceira Via.

O segundo texto, "Os debates iniciais do Plano Nacional de Educação (2001-2020): uma análise do modelo de participação social do governo Lula", escrito pela professora Andréia Ferreira da Silva, analisa, inicialmente, o modelo da relação entre Estado e sociedade civil instituído pelo Governo Lula, no período 2003-2010, examinando a realização da CONAE, em março de 2010, nos marcos desse modelo. Por fim, aponta os limites e omissões do Projeto de Lei $n^{\circ}$ 8.035, de 20 de dezembro de 2010, encaminhado pelo governo ao Congresso Nacional, em relação ao documento que foi aprovado pela CONAE 2010.

Segundo Silva (2013), o modelo de participação proposto pelo governo Lula situa-se nos marcos do Neoliberalismo de Terceira Via, que visa construir uma coesão social e a legitimidade do Estado por meio da ampliação dos espaços de participação. No entanto, essa participação deve subordinar-se ao governo e estar pautada na conciliação de classes. Nesta visão, a CONAE é compreendida como um espaço para construção de consensos em torno das políticas educacionais em curso.

André Silva Martins dá sequência às reflexões com o trabalho intitulado "Classe Empresarial e o Plano Nacional de Educação: uma análise sobre um processo ainda em curso", no qual analisa o posicionamento de setores da classe empresarial brasileira sobre o PNE. A partir do governo FHC, políticas educacionais vêm se alinhando às expectativas desta classe. No Governo Lula, os empresários passaram a intervir, mais diretamente, na formulação da política educacional. Um exemplo, dessa atuação consiste no movimento Todos Pela Educação, considerado por Martins (2013) como um grupo de intelectuais orgânicos da classe empresarial. O Plano de Desenvolvimento da Educação (2007) incorporou as formulações deste movimento, que, também, foram consideradas no Projeto de Lei do PNE atual. Na análise de Martins (2013), na sociedade de classes todos os 
enunciados políticos e econômicos possuem a marca das classes, dessa forma, o projeto de PNE do governo tem a marca do empresariado.

No artigo "Um novo PNE: mais do mesmo na garantia do direito à educação", Antônio Lisboa Leitão de Souza apresenta "elementos da conjuntura político-econômica nacional e internacional e o primado até hoje exercido pela equipe econômica em detrimento das áreas sociais" ( $p$. 122) para questionar a eficácia e efetividade no novo PNE proposto pelo governo. Segundo o autor, o direito à educação pública, gratuita, democrática e de qualidade socialmente referenciada pressupõe uma sociedade efetivamente democrática, com a participação dos diversos setores organizados, e a definição de qualidade em educação que não se limite à sua dimensão quantitativa.

Souza (2013) aponta que a participação social deve ser estendida às instâncias de elaboração das políticas educacionais, que, no caso da elaboração do novo PNE, exigiria uma avaliação autônoma e independente do PNE expirado em 2010. Dessa forma, o autor conclui que sem uma mobilização social em torno da definição da agenda educacional brasileira, provavelmente, teremos uma PNE que expresse os interesses econômicos em detrimento das necessidades e demandas da sociedade.

Adriana Almeida Sales de Melo assina o texto "Questões sobre o financiamento da educação no Brasil: O PL n 8.035/2010". O artigo tem como pano de fundo teórico-metodológico, as influências dos organismos internacionais sobre a educação e a criação de uma agenda internacional para o setor, seguindo um viés neoliberal, que tem como um dos seus pilares centrais a privatização.

A autora afirma, a partir da análise das questões ligadas ao financiamento da educação, no Projeto de Lei $n^{\circ}$ 8.035/2010, que a proposta do Governo para o PNE tem como um dos seus objetivos o "estímulo direto aos movimentos de privatização da educação" (p. 141). Segundo Melo (2013), o texto do PL apresenta uma indefinição proposital entre as responsabilidades do setor público e da iniciativa privada na oferta 
da educação pública, possibilitando de forma implícita o uso privado dos recursos públicos do setor.

Apresenta a elaboração do novo PNE como uma ação da Nova Pedagogia da Hegemonia, destacando que a incorporação de intelectuais com um histórico de defesa da educação pública ao projeto de sociedade do Governo Federal, liderado por Lula, contribuiu para "a aceitação social das propostas governistas entre as entidades herdeiras do Fórum Nacional em Defesa da Educação Pública" (p. 132).

Com relação ao tema do financiamento, Melo (2013) mostra que os princípios aprovados na CONAE (2010) não foram inseridos no PL $n^{\circ}$ 8.035/2010, como a construção do custo aluno-qualidade, a aplicação dos recursos públicos exclusivamente nas instituições públicas de ensino e a ampliação do investimento em educação pública de forma a atingir, no mínimo, 10\% do PIB até 2014.

O livro é finalizado com o texto "O trabalho docente no Plano Nacional de Educação (PNE) 2011-2020: uma discussão necessária", de Melânia Mendonça Rodrigues, que considera "O PNE/2011 como continuidade e aprofundamento da política educacional implementada desde as reformas da segunda metade dos anos de 1990" (p. 147). O PNE (2001-2010) esteve inserido num cenário de precarização do trabalho docente, com a flexibilização das relações trabalhistas, a intensificação do trabalho, a responsabilização individual dos professores por sua formação, além do enfraquecimento da dimensão ético-política dos movimentos organizados dos trabalhadores da educação.

Rodrigues (2013) aponta uma tensão, na virada da primeira década do século XXI, entre a valorização e a responsabilização docente. A inclinação para esta última pode ser traduzida na não compatibilidade entre a proclamada prioridade da valorização do professor e o texto do PNE 2001, que estabeleceu garantias, mas não explicitou os meios para a sua efetivação. 
A despeito das duas metas sobre a valorização no PL n 8.035/2010, a que prevê a equiparação salarial dos profissionais do magistério aos demais profissionais com escolaridade equivalente e a que prevê os planos de cargos e carreiras, Rodrigues (2013) compreende, respectivamente, que suas estratégias pouco repercutirão em melhorias nas condições materiais do trabalho docente, visto que são apresentadas sem clareza e objetividade, e que a efetividade dessas estratégias encontra-se condicionada pelos limites do pacto federativo brasileiro.

As questões levantadas pelos autores ao longo dos capítulos, acerca das tensões e debates que envolveram a elaboração do Novo Plano Nacional de Educação (PNE), contribuem para uma compreensão crítica das políticas educacionais em vigor no país, tornando-se uma leitura recomendada aos pesquisadores e estudantes da área que pretendem ampliar seu olhar acerca da agenda implantada no país nos últimos anos.

Recebida em: Outubro de 2016 Aceita em: Dezembro de 2016 